\title{
Shift-share Analysis on International Tourism Competitiveness -A Case of Jiangsu Province
}

\author{
SHI Chunyun ${ }^{1,2}$, ZHANG Jie ${ }^{1}$, YANG Yang ${ }^{3}$, ZHOU Zhang ${ }^{4}$ \\ (1. School of Geographic and Oceanographic Sciences, Nanjing University, Nanjing 210093, China; \\ 2. School of Urban and Environmental Sciences, Xuzhou Normal University, Xuzhou 221116, China; \\ 3. Center for Recreation and Tourism Research, Peking University, Beijing 100871, China; \\ 4. Jiangsu Tourism Administration, Nanjing 210003, China)
}

\begin{abstract}
Shift-share analysis has been confirmed a useful approach in the study of regional economics and many kinds of extended shift-share models have been advanced and put into practice in economic studies, but few have hitherto been introduced and applied to the tourism research in China. Moreover understanding the spatially competitive relationship is of paramount importance for marketers, developers, and planners involved in tourism strategy development. Based on international tourism receipts from 1995 to 2004, this study aims at probing into the spatial competitiveness of international tourism in Jiangsu Province in comparison with its neighbors by applying a spatially extended shift-share model and a modified dynamic shift-share model. The empirical results illustrate that exceptional years may exist in the application of dynamic shift-share models. To solve this issue, modifications to dynamic shift-share model are put forward. The analytical results are not only presented but also explained by the comparison of background conditions of tourism development between Jiangsu and its key competitors. The conclusions can be drawn that the growth of international tourism receipts in Jiangsu mainly attributes to the national component and the competitive component and Zhejiang is the most important rival to Jiangsu during the period of 1995-2004. In order to upgrade the tourism competitiveness, it is indispensable for Jiangsu to take proper positioning, promoting and marketing strategies and to cooperate and integrate with its main rivals.
\end{abstract}

Keywords: international tourism competitiveness; spatially extended shift-share analysis model; comparative static shift-share analysis; modified dynamic shift-share analysis; Jiangsu Province

\section{Introduction}

The original formulation of shift-share method was first advanced by Creamer (1943) and then was summarized and induced by Dunn (1960). Shift-share analysis has generally been used for describing regional and industrial economic growth and examining the structural effect and regional or industrial competitiveness underlining the changes. It has been a very powerful tool for measuring the changes over time in regional economics, marketing, urban studies, etc. Stevens and Moore (1980) put forward that the factor to account for its popularity is the technically simple procedure. Shift-share analysis requires only less data that are generally accessible. Despite its simplicity, it does well in capturing the underlining changes in the variables under consideration (Nazara and Hewings, 2004) and making the analysis fast and reasonably accurate.

Shift-share analysis has just been applied to tourism industry in recent years (Sirakaya et al., 1995; Fuchs et al., 2000; Alavi and Yasin, 2000; Sirakaya et al., 2002; Toh et al., 2001; 2003; 2004; Yasin et al., 2004). Employment, arrivals and receipts are usually used as variables to measure changes in the shift-share models (Shi et al., 2007). Only in recent years have a few studies using shift-share analysis focused on sectoral structure and competitiveness within tourism industry in China (Yang et al., 2005; Wen and Wang, 2005; Chu, 2005; Li and Cheng, 2004; Wang et al., 2004). Moreover, although many kinds of extended shift-share models have been

Received date: 2006-06-25; accepted date: 2007-03-18

Foundation item: Under the auspices of the National Natural Science Foundation of China (No. 40371030)

Biography: SHI Chunyun. E-mail: shichunyun@163.com 
advanced, the application of the models to tourism research in China mainly limits to the comparative static model of shift-share analysis. Thus this study aimed at applying both spatially extended shift-share analytical approach and modified dynamic model to tourism spatial competitiveness of Jiangsu Province based on international tourism receipts from 1995 to 2004 .

\section{Methodology}

\subsection{Comparative static model and its extended models}

Traditional shift-share analysis is used to decompose regional growth over time into three effects: the national growth effect, the industry-mixed effect, and the competitive effect, which is generally applied in a study period of several years and examines conditions only at the beginning and the end years. In such a comparative static approach, the subtle swings during the study periods were lost (Sirakaya et al., 1995). The inherent limitations of this comparative static method, however, can be overcome by calculating the shift-share effects on a multiple-year data on the basis of creating dynamic, time-series-like data (Sirakaya et al., 2002). The dynamic shift-share analysis is an extension of Thirlwall's (1967) suggestion that the study period be divided into two or more sub-periods to reduce the severity of the changes. It provides a more accurate allocation of changes to calculate the national growth effect, the industry-mixed effect, and the competitive effect on an annual basis and then sum the results over the study period. One of the key advantages of this dynamic shift-share analysis is that it enables changes to be tracked over the years without losing information in those periods and allows unusual years and years of economic transition to be identified (Sirakaya et al., 2002).

The current decomposition posits a strictly hierarchical view of influence - the nation influences the regions, but regions do not influence each other. However, the general idea is that the decomposed effects are not spatially independent, and the performance of surrounding regions, of regions with similar structures, or of regions that are dominant trading partners will all have an influence on the growth performance of a particular region (Nazara and Hewings, 2004). Here an extended shift-share model newly put forward by Nazara and Hewings should be emphasized on for the further study. They first incorporate spatial structure within shift-share analysis, to take interregional interaction into account in the decomposition analysis. Given the relatively recent conceptualization of such an extended model, it is not surprising that the approach is needed to be tested empirically.

\subsection{Methods in this study}

Nazara-Hewings' extended industrial model of the shift-share formulation can be represented into three distinct effects as Equation (1).

$$
g_{i}=G_{i}+\left(g_{i}^{\prime}-G_{i}\right)+\left(g_{i}-g_{i}^{\prime}\right)
$$

where $g_{i}$ denotes the actual growth of international tourism receipts in the study region, $g_{i}^{\prime}$, that in the neighboring regions, $G_{i}$ denotes the national counterpart, and $i$, the peculiar sector, i.e. international tourism receipts in the study. Here, Jiangsu Province is the study unit while its neighboring regions are used as benchmark areas. Compared with the traditional shift-share analysis, Equation (1) reflects two changes. First, only sectoral growth over time is measured here, which can be called purely industrial model. Nazara-Hewings' extended model offers varied forms so that appropriate form may be selected in terms of the study's requirement. Second, besides the whole nation and peculiar area, neighboring region is included here, which can reflect how the study unit interacts with its neighbor and which region is on earth the most important competitor to the study unit.

Figure 1 denotes the formulation and explanation of shift-share analysis in this study, where $R_{j}^{0}, R_{G}^{0}, R_{g}^{0}$ represent international tourism receipts of neighboring region, nation and the study region at the beginning year respectively, while $R_{j}^{t}, R_{G}^{t}, R_{g}^{t}$ denote the amount at the end of the period. Actual growth of international tourism receipts in Jiangsu Province from 1995 to 2004 can be decomposed into three components, the national sectoral shift effect, neighbor-national sectoral shift effect and regional-neighbor sectoral shift effect (also called competitive effect).

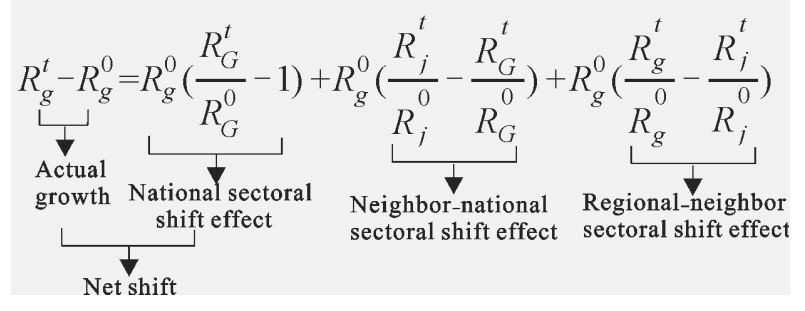

Fig. 1 Shift-share formulation 


\section{Case Study}

\subsection{Study area and data}

The eastern coastal China has always been considered an interesting and relevant location. Six provinces in the eastern coastal China are chosen as samples for this study. The study area includes Jiangsu, the target region, and its neighboring regions, such as Shanghai, Zhejiang, Anhui, Shandong and Henan. The study period spans ten years from 1995 to 2004 during which continuous time series data are available for all the provinces under examination. In 2004 Jiangsu positioned the fourth international destination in China. The persistent augment trend of international tourism receipts in both Jiangsu and its neighbors can be clearly seen from Table 1 . Jiangsu's share of Chinese international tourism receipts increased from $3.15 \%$ to $8.39 \%$ during $1995-2004$ while the whole study area's share from $20.37 \%$ to $33.15 \%$. Thus Jiangsu and its neighbors are regarded as one of the most significant international destinations and foreign exchange earners in China.

\subsection{Results}

Table 2 provides the analytical results of the comparative static and dynamic shift-share models. Due to the abnormal severity resulted from typical exogenous factor of Severe Acute Respiratory Syndrome (SARS) outbreak in 2003, such abnormal changes, which are extraordinarily different from those in normal milieu, will be not as the basis of measuring the swings of industries accurately and truly. In order to eliminate such abnormal impact, the data of 2003 are omitted and a two-year interval from 2002 to 2004, associated with other annual interval, is included. We term it modified dynamic model, which can not only overcome the inherent limitations of the traditional comparative static method, but also avoid the severe and abnormal changes of individual year in general dynamic model.

\subsubsection{National sectoral shift effect}

From the results in Table 2, 26.7\% of the actual growth in comparative static model is attributable to the national sectoral shift effect while $41.3 \%$ in modified dynamic model, $50.9 \%$ in general dynamic model. Such findings

Table 1 International tourism receipts in 1995-2004 (US\$10 $\left.{ }^{6}\right)$

\begin{tabular}{lrrrrrrrrrr}
\hline & 1995 & 1996 & 1997 & 1998 & 1999 & 2000 & 2001 & 2002 \\
\hline Jiangsu & 260 & 317 & 408 & 529 & 620 & 724 & 822 & 1050 & 1132 & 1763 \\
Shanghai & 939 & 1171 & 1317 & 1218 & 1364 & 1613 & 1808 & 2275 & 2053 & 3041 \\
Zhejiang & 236 & 292 & 345 & 361 & 410 & 514 & 699 & 928 & 873 & 1300 \\
Anhui & 31 & 42 & 64 & 51 & 67 & 86 & 106 & 124 & 83 & 141 \\
Shandong & 154 & 196 & 204 & 220 & 265 & 315 & 382 & 472 & 3703 & 567 \\
Henan & 60 & 73 & 95 & 101 & 114 & 124 & 133 & 145 & 64 & 160 \\
China & 8249 & 9476 & 10428 & 10760 & 12009 & 14327 & 15968 & 18531 & 14410 & 21031 \\
\hline
\end{tabular}

Source: National Bureau of Statistics of China, 2006

Table 2 Results comparisons of dynamic and comparative static shift-share models in 1995-2004 (US\$10 ${ }^{6}$ )

\begin{tabular}{|c|c|c|c|c|}
\hline & & $\begin{array}{c}\text { Dynamic shift-share } \\
\text { model }\end{array}$ & $\begin{array}{c}\text { Static shift-share } \\
\text { model }\end{array}$ & $\begin{array}{l}\text { Modified shift-share } \\
\text { model }\end{array}$ \\
\hline \multicolumn{2}{|l|}{ Actual growth } & 1503.44 & 1503.44 & 1503.44 \\
\hline \multicolumn{2}{|l|}{ National sectoral shift effect } & 765.98 & 402.86 & 621.09 \\
\hline \multicolumn{2}{|l|}{ Net shift } & 737.46 & 1100.58 & 882.35 \\
\hline \multirow{5}{*}{$\begin{array}{l}\text { Neighbor-national sectoral } \\
\text { shift effect }\end{array}$} & Shanghai-nation & 226.11 & 179.23 & 282.14 \\
\hline & Zhejiang-nation & 623.59 & 769.86 & 697.51 \\
\hline & Anhui-nation & 493.02 & 517.12 & 345.65 \\
\hline & Shandong-nation & 296.62 & 293.65 & 277.80 \\
\hline & Henan-nation & 793.04 & 30.52 & -85.74 \\
\hline \multirow{5}{*}{$\begin{array}{l}\text { Regional-neighbor sectoral } \\
\text { shift effect }\end{array}$} & Jiangsu-Shanghai & 511.35 & 921.35 & 600.20 \\
\hline & Jiangsu-Zhejiang & 113.88 & 330.72 & 184.84 \\
\hline & Jiangsu-Anhui & 244.44 & 583.46 & 536.70 \\
\hline & Jiangsu-Shandong & 440.84 & 806.93 & 604.55 \\
\hline & Jiangsu-Henan & -55.57 & 1070.06 & 968.09 \\
\hline
\end{tabular}

are identical to conclusions advanced by Barff and Knight (1988) that the national growth effect is underestimated by the comparative static approach during periods when regional growth rate exceeds the national rate. Both the dynamic and comparative static approaches show that Jiangsu Province has an actual growth of US\$1503.44 $\times 10^{6}$ 
and a positive net shift, which means that Jiangsu performs better relative to the whole country in the development of the international tourism industry. Indeed, the national sectoral shift effect has been positive, which indicates that the international tourism receipts are secured due to the national growth trend and implies that tourism industry is one of the most flourishing sectors in China.

\subsubsection{Neighbor-national sectoral shift effect}

From the neighbor-national sectoral shift effect, all the neighbors of Jiangsu except Henan have positive value both in dynamic model and in static model, which suggests that the development of international tourism industry is faster than the average of national growth and tourism industry has been becoming one of the industries with a high propensity to grow in the study area. Particularly, the growth of Zhejiang and Anhui are well in excess of that of the others. Despite a relative uniformity in most of neighbor-national sectoral shift effects, Henan's effect by general dynamic approach reveals a much stronger growth (US $\$ 793.04 \times 10^{6}$ ) than those (US\$ $30.52 \times 10^{6}$, US $\$-85.74 \times 10^{6}$ ) do by static approach and modified model because of the exceptional year of 2003 in Henan.

\subsubsection{Competitive effect}

Jiangsu also has positive competitive effects over all its neighboring regions, meaning that it is more competitively positioned with respect to its neighbors. However, Zhejiang has the least value both in comparative static and in modified dynamic model, which means Zhejiang develops much proximate to Jiangsu in international tourism industry. Furthermore, it can be inferred that Zhejiang is the most important competitor to Jiangsu. Detailed results are listed in Table 3. In fact, changes during these ten years have greatly fluctuated. The net shifts seemed to be too modestly positive in 1999 and 2001 and even displayed negative in 2000 , meaning that the performance of international tourism industry in Jiangsu was so poor that its actual growth was even less than that of the whole China in 2000. Nevertheless, international tourism receipts in Jiangsu has been increasing explosively since 2002, even in the exceptional year of 2003 when the SARS outbreak almost devastated the whole national tourism and the study area, all but Jiangsu have endured a negative gain. Jiangsu has experienced fluctuations, but still followed a rising trend.

International tourism industrial competitiveness in Jiangsu has been expected to increase gradually with the time by the spatial-temporal series analysis of the de-
Table 3 Dynamic shift-share analysis of Jiangsu Province (US $\$ 10^{6}$ )

\begin{tabular}{lrcr}
\hline & Actual growth & $\begin{array}{c}\text { National sec- } \\
\text { toral shift effect }\end{array}$ & Net shift \\
\hline $1995-1996$ & 57.05 & 38.68 & 18.37 \\
$1996-1997$ & 90.95 & 31.84 & 59.11 \\
$1997-1998$ & 121.00 & 12.99 & 108.01 \\
$1998-1999$ & 91.00 & 61.41 & 29.59 \\
$1999-2000$ & 104.00 & 119.67 & -15.67 \\
$2000-2001$ & 98.02 & 82.90 & 15.12 \\
$2001-2002$ & 227.98 & 131.97 & 96.01 \\
$2002-2003$ & 81.87 & -233.49 & 315.36 \\
$2003-2004$ & 631.57 & 520.00 & 111.57 \\
\hline
\end{tabular}

velopment trend of regional competitive component (Table 4). Compared with Anhui Province, most of the annual regional competitive components before 2001 are negative, which indicates that Anhui has done a better job in attracting more international tourists or encouraging much more consumption than Jiangsu has. However, Jiangsu has been experiencing a much swifter increase than Anhui since 2002 and has well exceeded Anhui since then. Compared with Zhejiang Province, regional competitive components were negative from 2000 to 2002. The international tourism industry in Zhejiang has been one of those industries with a high propensity to grow since 2000 and displays advantages both in the whole country and in the prosperous eastern China. Due to the swift development of international tourism in Jiangsu in 2003 and 2004, Zhejiang failed to exhibit any more competitive advantage. In conclusion, Jiangsu has greater competitiveness in the international tourism industry in terms of the analytical results, while Zhejiang Province can be viewed as the most important rival for Jiangsu among all the neighboring regions both by comparative static and by modified dynamic shift-share models. Although dynamic shift-share model can overcome some temporal limitations of comparative static model, it cannot answer the perplexing questions and make any judgments about the likely causes for competitive advantages or disadvantages (Yasin et al., 2004). To seek explanations for this, we would need to carry out further analysis in comparison with local conditions.

\subsection{Discussion}

It is of very importance for marketers, developers, and planners involved in strategy development to clearly understand the spatially competitive situation for the development of international tourism industry in Jiangsu. 
Table 4 Regional competitive effect by modified dynamic model

\begin{tabular}{|c|c|c|c|c|c|c|c|c|}
\hline & $1995-1996$ & $1996-1997$ & $1997-1998$ & $1998-1999$ & 1999-2000 & 2000-2001 & 2001-2002 & $2002-2004$ \\
\hline Jiangsu-Shanghai & -7.08 & 51.30 & 151.67 & 27.59 & -9.18 & 10.62 & 15.49 & 359.79 \\
\hline Jiangsu-Zhejiang & -4.47 & 33.20 & 102.08 & 19.20 & -53.27 & -162.41 & -41.49 & 292.00 \\
\hline Jiangsu-Anhui & -35.21 & -75.12 & 203.88 & -74.96 & -71.82 & -67.66 & 85.48 & 572.11 \\
\hline Jiangsu-Shandong & -14.69 & 78.83 & 89.00 & -17.20 & -12.98 & -56.92 & 35.40 & 503.11 \\
\hline Jiangsu-Henan & 1.15 & -5.17 & 95.23 & 22.91 & 49.61 & 43.37 & 156.23 & 604.75 \\
\hline
\end{tabular}

Actually, further analysis of the background and conditions in Jiangsu and Zhejiang can not only empirically prove the findings of the above shift-share analytical results, but also lay a foundation for making strategies for the development of the tourism industry.

\subsubsection{Competition analysis}

(1) Similar location conditions. Both these two regions are situated at the Changjiang River estuary and facing with the sea, being important belt of eastern China's reform and opening up. They are also close to and dependent on Shanghai, China's biggest industrial base and trade port. Findings from Zhang et al. (2000) indicated that Shanghai is the significant distributing center for the inbound and outbound tourists flow for both Jiangsu and Zhejiang.

(2) Same culture milieu. These two regions belong to the WU and YUE cultural districts well known as the "first prosperous cultural relic" ( $\mathrm{Hu}$ and Sun, 2005). Elites in politics, culture, science, technology, art, etc., have come forth in great number since the Tang Dynasty, which is profound and is responsible for the whole Chinese history and for the prosperity nowadays in the famous Changjiang River Delta to a large degree.

(3) Similar tourism resources and characteristics. These two regions are famous for the "water country" because of its numerous lakes, rivers, streams and estuaries, and are usually referred to as "lands of fish and rice" because of abounding in rice paddies, mulberry orchards and fishponds. An old saying in China, "There is a paradise in the heaven and Suzhou, Hangzhou on the earth", tells us both the scenic beauty and the similar resources and tourism image in the two regions.

(4) Similar tourism development impetus. About $39.3 \%$ of the inbound tourists in Jiangsu and $47.1 \%$ in Zhejiang were for business-related activities in 2004, which particularly illustrates the importance of the economic impetus to tourism development in the two regions. The remarkable economic and trade growth have been accompanied by persistent inbound tourist flows to the study region.
(5) Similar origin market structure. The main tourists origin markets in two provinces are much alike. Their Spearman's correlation coefficient is 0.829 and significant at the 0.01 level (2-tailed). However, they all have lower correlation coefficient with the whole China, 0.521 and 0.648 respectively and only significant at the 0.05 level, which means the two regions have similar structure of tourist origins though they are some different from the whole China.

\subsubsection{Strategy development}

As described above, there is little doubt that Jiangsu and Zhejiang share much similarity in terms of the development of tourism industry and exhibit close competitive relation to each other. Therefore, understanding competitors and taking proper strategies are of great significance. With these considerations in mind, we can make several recommendations. First, from supply-side perspective comes recognition of the importance of the tourism product positioning in carrying out differentiation and individuation strategies due to so many similarities in the two provinces. Second, from market-side perspective comes recognition of the importance of promoting and marketing in attracting more inbound tourists to retain the sustainable development of the international tourism industry. Finally, cooperation will be an effective way to improve the competitiveness for each other. Starting with exploiting the tourism market, constituting tourism policy and laws and constructing tourism standardization, Jiangsu, Zhejiang and Shanghai have set out to build the cooperation framework of regional tourism, reinforce the policy auspice for regional economic integration, eliminate regional administrative and policy wall, and establish regional non-obstacle travel pattern among Jiangsu, Zhejiang and Shanghai.

\section{Conclusions}

In the empirical application, the findings reflect that tourism industry is booming and has continuous prosperity in China. Both Jiangsu and most of its neighboring 
regions have positive growth rates in comparison with the whole China, which suggests that these regions are becoming one of the fastest-growing markets in China. Moreover, Jiangsu has positive competitive effect over all its neighboring regions, meaning that it was more competitively positioned with respect to its entire neighbor. Zhejiang is the most important rival to Jiangsu as far as international tourism industry is concerned since these two provinces share many similarities with each other, which can be considered as the key reasons for competitive relationship.

However, the shift-share analysis has its inherent limitations. The model can not give the mechanism and explanation underlying the changes but describe and reflect the spatially competitive state. In order to make it clear, further study and analysis should be needed.

\section{References}

Alavi J, Yasin M, 2000. A systematic approach to tourism policy. Journal of Business Research, 48: 147-156.

Barff R A, Knight III P L, 1988. Dynamic shift-share analysis. Growth and Change, 19: 1-11.

Chu Xinzheng, Li Yanhong, Jin Wangui, 2005. Analysis on international tourism industry structure and benefit in Xinjiang. Journal of Arid Land Resources and Environment, 19(4): 119-124. (in Chinese)

Creamer D, 1943. Shifts of manufacturing industries. In: Industrial Location and National Resources. Washington, D C: Government Printing Office.

Dunn J E S, 1960. A statistical and analytical technique for regional analysis. Papers of the Regional Science Association, 6: 97-112.

Fuchs M, Rijken L, Peters M et al., 2000. Modeling asian incoming tourists: A shift-share approach. Asia Pacific Journal of Tourism Research, 5(2): 1-10.

Hu Zhaoliang, Sun Huishu, 2005. Outline of Cultural Geography in China. Beijing: People's Education Press, 261. (in Chinese)

Li Deming, Cheng Jiumiao, 2004. On the structure and optimization measures of international tourism industry in Anhui Province. Resources Development and Market, 20(5): 390-392. (in Chinese)

National Bureau of Statistics of China, 2006. China Statistical Yearbook. Beijing: China Statistics Press. (in Chinese)
Nazara S, Hewings G J D, 2004. Spatial structure and taxonomy of decomposition in shift-share analysis. Growth and Change, 35(4): 476-490.

Shi Chunyun, Zhang Jie, Gao Wei et al., 2007. Review of shift-share analysis and its extended models abroad. Inquiry into Economic Issue, 3: 133-136.

Sirakaya E, Choi Hwan-Suk, Var T, 2002. Shift-share analysis in tourism: examination of tourism employment change in a region. Tourism Economics, 8(3): 303-24.

Sirakaya E, Uysal M, Toepper L, 1995. Measuring the performance of South Carolina's tourist industry from shift-share analysis: A case study. Journal of Travel Research, 33(2): 55-62.

Stevens B H, Moore C L, 1980. A critical review of the literature on shift-share as a forecasting technique. Journal of Regional Science, 20: 419-437.

Thirlwall A P, 1967. A measure of the proper distribution of industry. Oxford Economic Papers, 19(March): 46-58.

Toh R S, Khan H, Koh Ai-Jin, 2001. A travel balance approach for examining tourism area life cycles: the case of Singapore. Journal of Travel Research, 39(3): 426-432.

Toh R S, Khan H, Lim L L, August 2004. Two-stage shift-share analyses of tourism arrivals and arrivals by purpose of visit: the Singapore experience. Journal of Travel Research, 43(1): 57-66.

Toh R S, Khan H, Yap I, 2003. An empirical validation of the travel balance approach as an alternative to the tourism area life cycle. Tourism Analysis, 7: 207-215.

Wang Changyan, Liu Yuntong, Zhang Xinhuan, 2004. Analysis on structural efficiency of tourism industry for overseas tourists in Xinjiang. Journal of Xinjiang Normal University (Natural Sciences Edition), 23(2): 74-79. (in Chinese)

Wen Fei, Wang Juan, 2005. Integrated analysis of the competitive state in domestic tourism industry of Anhui Province. Journal of Huangshan University, 7(4): 17-30. (in Chinese)

Yang Xinjun, Ma Xiaolong, Huo Yunpei, 2005. A SSM analysis rationality of sector structure of tourism industry. Human $\mathrm{Ge}$ ography, 20(1): 49-52. (in Chinese)

Yasin M, Alavi J, Sobral F et al., 2004. A shift-share analysis approach to understanding the dynamic of the Portuguese tourism market. Journal of Travel and Tourism Marketing, 17(4): $11-22$.

Zhang Hong, Li Jiuquan, Yang Zhaoping et al., 2000. A study on the structure features and spatial and temporal dynamic mode of overseas tourists in Xi'an. Arid Land Geography, 23(2): 165-169. (in Chinese) 